\title{
Determinants of Bribery: Theory and Evidence from Sub-Saharan Africa
}

\section{Riccardo Pelizzo, Eduardo Araral, Anton Pak, Wu Xun}

\author{
Graduate School of Public Policy
}

\section{Abstract}

The paper investigates the determinants of bribery in sub-Saharan Africa by using probit models and data from the World Bank's Enterprise Survey of 10,457 firms in 30 countries in sub-Saharan Africa from 2009 to 2013. By doing so we find that securing a government contract is the most significant motivation for bribery and that overall, the propensity to bribe depends on the size of the firm as well as the predictability of the regulatory environment. Our findings have similarities and differences compared to Asian firms. The paper also highlights that the incidence and the determinants of bribery vary across the four sub-regions. On the basis of this evidence we suggest that when it comes to anti-corruption strategies, one size does not fit all and that country-specific and region-specific strategies should be adopted to address context-specific needs and conditions.

$\begin{array}{ll}\text { Original language } & \text { English } \\ \text { Pages (from-to) } & 229-240 \\ \text { Number of pages } & 12 \\ \text { Journal } & \text { African Development Review } \\ \text { Volume } & 28 \\ \text { Issue number } & 2 \\ \text { State } & \text { Published - Jun 1 2016 }\end{array}$

Pelizzo, R., araral, E., pak, A., \& xun, W. (2016). Determinants of Bribery: Theory and Evidence from Sub-Saharan Africa. African Development Review, 28(2), 229-240. 